\title{
ANALISIS KELIMPAHAN FITOPLANKTON BERDASARKAN KETERSEDIAAN NUTRIEN DI RANU GRATI DENGAN GENERALIZED POISSON REGRESSION
}

\author{
Evellin Dewi Lusiana $^{a, b, *}$, Mohammad Mahmudi ${ }^{a, b}$, Nanik Retno Buwono ${ }^{a, b}$, Tisya W. Nisya ${ }^{b}$ \\ ${ }^{a}$ Program Studi Manajemen Sumber Daya Perairan, Fakultas Perikanan dan Ilmu Kelautan, \\ Universitas Brawijaya, Jalan Veteran, Malang, Indonesia \\ b AquaRES Research Group, Fakultas Perikanan dan Ilmu Kelautan, Universitas Brawijaya, \\ Jalan Veteran, Malang, Indonesia \\ *Koresponden penulis : evellinlusiana@ub.ac.id
}

\begin{abstract}
Abstrak
Fitoplankton adalah organisme akuatik yang memegang peranan penting di ekosistem perairan karena merupakan produsen utama dalam rantai makanan. Pertumbuhan fitoplankton sangat tergantung dari ketersediaan nutrient (nitrat dan fosfat) yang ada di perairan. Ranu Grati adalah danau vulkanis yang terletak di Jawa Timur yang banyak dimanfaatkan oleh masyarakat untuk berbagai aktivitas. Aktivitas-aktivitas tersebut umumnya menghasilkan bahan organik yang akan mempengaruhi konsentrasi nitrat dan fosfat sekaligus juga mempengaruhi struktur komunitas fitoplankton di perairan danau. Penelitian ini bertujuan untuk memodelkan hubungan kelimpahan fitoplankton dengan ketersediaan nutrient serta memprediksi komposisi fitoplankton berdasarkan divisi untuk mengetahui struktur komunitasnya dengan pendekatan Generalized Linear Regression. Hasil analisis menunjukkan bahwa nutrient yang berpengaruh signifikan terhadap jumlah amatan fitoplankton adalah konsentrasi fosfat, sedangkan kelimpahan fitoplankton di Ranu Grati cenderung didominasi oleh fitoplankton dari divisi Chlorophyta.
\end{abstract}

Kata kunci: Count data; fitoplankton; nitrat; fosfat; overdispersi

\begin{abstract}
Phytoplankton are aquatic organisms that play an important role in aquatic ecosystems because they are the main producers of the food web. Phytoplankton growth is highly dependent on the availability of nutrients (nitrates and phosphates) in the waters. Ranu Grati is a volcanic lake located in East Java which is widely used by the community for various activities. These activities generally produce organic matter which will affect the concentration of nitrate and phosphate as well as affect the structure of phytoplankton communities in lake. This study aimed to model the relationship between phytoplankton abundance and nutrient availability and to predict the composition of phytoplankton by division to determine the community structure using the Generalized Linear Regression approach. The analysis showed that the nutrient that had a significant effect on the number of phytoplankton observed was the concentration of phosphate, while the abundance of phytoplankton in Ranu Grati tended to be dominated by phytoplankton from the Chlorophyta division.
\end{abstract}

Keywords: Count data; phytoplankton; nitrate; phosphate; overdispersion

\section{PENDAHULUAN}

Danau merupakan cekungan yang berisi air baik secara permanen maupun sementara yang menjadi bagian dalam perairan di daratan [1]. Sebagian besar danau yang ada di Indonesia terbentuk akibat aktivitas vulkanis. Ranu Grati merupakan salah satu danau vulkanik yang terletak di Provinsi Jawa Timur. Ranu Grati banyak dimanfaatkan oleh masyarakat sekitar sebagai sumber irigasi pertanian, karamba jaring apung dan pariwisata. Kegiatan-kegiatan tersebut menghasilkan limbah yang kemudian dibuang ke perairan danau [2]. Hal ini akan mempengaruhi kesuburan dan organisme yang ada di danau, termasuk di dalamnya adalah fitoplankton [3].

Fitoplankton memiliki peran yang sangat penting dalam perairan sebagai produsen utama bagi organisme akuatik lainnya karena kemampuannya untuk melakukan proses fotosintesis. Pertumbuhan fitoplankton tergantung dari ketersediaan nutrien yang ada 
di perairan yaitu nitrat $(\mathrm{N})$ dan fosfat $(\mathrm{P})$ [4]. Nitrat dan fosfat biasanya digunakan sebagai unsur pembatas bagi pertumbuhan fitoplankton yang dikenal sebagai Redfield ratio. Di sisi lain, keberadaan unsur-unsur nutrient secara berlebihan di perairan justru akan mengakibatkan ledakan fitoplankton yaitu suatu keadaan dimana kelimpahan fitoplankton sangat tinggi. Hal ini akan berdampak pada kematian massal ikan-ikan dan organisem lain dalam air [5].

Keterkaitan antara kelimpahan fitoplankton dan nutrien biasanya dianalisis dengan pendekatan regresi linier [6]-[8]. Adapun yang dianalisis adalah pengaruh kadar nutrient terhadap kelimpahan fitoplankton secara keseluruhan. Penelitian ini bertujuan untuk membuat model kelimpahan fitoplankton menurut divisi yang teramati berdasarkan ketersediaan nutrien nitrat dan fosfat, sehingga dapat dibuat prediksi terhadap komposisi kelimpahan fitoplankton di Ranu Pakis. Model yang digunakan dalam penelitian ini adalah model untuk count data. Salah satu jenis model count data yang dapat digunakan adalah model regresi Poisson [9]. Namun, model ini mensyaratkan rata-rata dan ragam dari variable respon yang dianalisis bernilai sama (equidispersi). Apabila rata-rata dan ragam tidak sama atau overdispersi, maka digunakan model Generalized Poisson Regression.

\section{METODE}

\section{Sumber Data}

Data yang digunakan dalam penelitian ini adalah data primer. Pengambilan data dilakukan selama bulan Januari-Februari 2019 di Ranu Grati, Kabupaten Pasuruan, Jawa Timur. Terdapat enam titik sampling yang disebut stasiun dalam penelitian ini (Gambar 1). Stasiun 1 adalah daerah outlet, Stasiun 2 daerah inlet, Stasiun 3-5 adalah daerah karamba jaring apung (KJA), dan stasiun 6 adalah daerah tengah danau.

Pengamatan dan identifikasi terhadap fitoplankton dilakukan secara ex-situ di Laboratorium Sumberpasir, Fakultas Perikanan dan Ilmu Kelautan, Universitas Brawijaya menggunakan metode Lackey Drop. Adapun pengukuran nitrat dan fosfat menggunakan spektrofotometer.

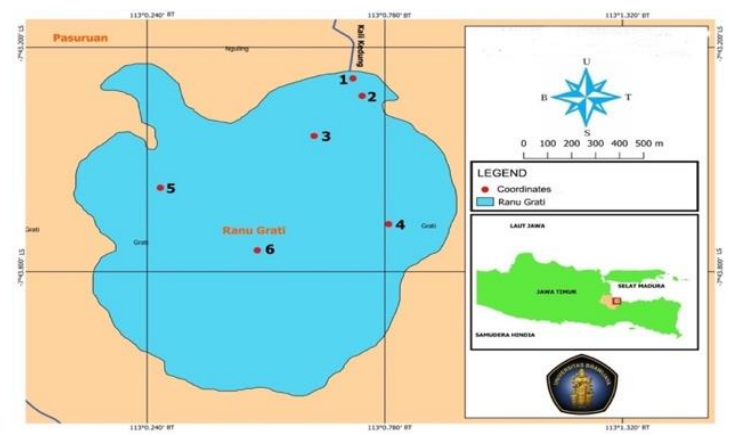

Gambar 1. Lokasi penelitian di Ranu Grati

\section{Model Regresi Poisson dan Generalized Poisson Regression}

Count data secara umum didefinisikan sebagai banyaknya peristiwa yang terjadi pada interval waktu tertentu. Jenis peristiwa yang akan diamati harus ditentukan dengan jelas sebelum pengamatan. Secara matematis, count data berupa bilangan bulat non-negatif karena suatu peristiwa terjadi secara utuh atau jumlahnya tidak bisa bernilai negatif karena bila peristiwa yang diamati tidak terjadi, maka amatan bernilai nol [10].

Pemodelan yang umum untuk count data adalah dengan menggunakan regresi Poisson. Model regresi ini diturunkan dari distribusi peluang Poisson dengan menjadikan parameternya yaitu tergantung pada satu atau sekelompok prediktor [11].

Suatu variable random Y dikatakan berdistribusi Poisson apabila peluang $\mathrm{Y}$ bernilai $\mathrm{y}=0,1,2,3, \ldots$ mengikuti fungsi (1) berikut

$f(Y=y)=\frac{{ }^{y} e}{y !} \quad \mathrm{y}=0,1,2,3, \ldots$

Di mana:

$\mu=$ rata-rata terjadinya peristiwa yang diamati pada interval waktu tertentu.

Distribusi peluang Poisson memiliki karakteristik $E(Y)=\operatorname{Var}(Y)=$.

Dengan kata lain, rata-rata dan ragam pada distribusi Poisson bernilai sama. Kondisi ini disebut sebagai equidispersi. Apabila ragam lebih besar daripada rata-rata maka disebut overdispersi, sedangkan jika ragam lebih kecil dari rata-rata maka disebut underdispersi [12]. Dalam praktiknya, kondisi overdispersi lebih sering terjadi akibat keterbatasan data yang 
tersedia [13]. Selain itu, masalah overdispersi mempengaruhi interpretasi model, sehingga identifikasi overdispersi menjadi penting untuk menghindari kesalahan estimasi parameter [14], [15]. Uji untuk menentukan overdispersi dapat dilakukan dengan uji Wald [11], [16].

Model regresi Poisson seringkali diterapkan pada data cross-section yang terdiri atas $n$ pengamatan yang saling independent, dengan pengamatan ke-i dapat dinyatakan sebagai $\left(y_{i}, \mathbf{x}_{i}\right)$, di mana $y_{i}$ merupakan banyaknya peristiwa amatan yang terjadi dan $\mathbf{x}_{i}$ adalah vector dari predictor-prediktor yang dianggap menentukan $y_{i}$ Model regresi berdasarkan distribusi bersyarat vector prediktor $\mathbf{x}_{i}^{t}=\left[x_{1 i}, \ldots, x_{k i}\right] \quad$ dan parameter $\quad \beta$ dinyatakan sebagai berikut

$$
f\left(y_{i} \mid \mathbf{x}_{i}\right)=\frac{e^{i} y_{i}}{y_{i} !} \quad \mathrm{y}_{i}=0,1,2,3, \ldots
$$

Sehingga

$$
E\left(y_{i} \mid \mathbf{x}_{i}\right)=\mu\left(\mathbf{x}_{i}, \boldsymbol{\beta}\right)=\exp \left(\mathbf{x}_{i}^{t} \boldsymbol{\beta}\right)
$$

atau

$\ln \left({ }_{i}\right)={ }_{0}+{ }_{1} x_{1 i}+{ }_{2} x_{2 i}+\ldots+{ }_{1} x_{k i}$

Persamaan (1) - (4) secara bersama-sama mendefinisikan model regresi Poisson. Estimasi parameter model regresi Poisson dilakukan dengan metode Maximum Likelihood Estimation (MLE), dengan fungsi likelihood (5)

$l\left({ }_{0, . .,}\right)={ }_{k=1}^{n}\left\{y_{i}\left({ }_{0}+{ }_{1} x_{i 1}+\ldots+{ }_{k} x_{i k}\right) \exp \left({ }_{0}+{ }_{1} x_{i 1}+\ldots+{ }_{k} x_{i k}\right)\right\}$

Apabila terjadi pelanggaran equidispersi, maka model regresi Poisson tidak dapat digunakan. Alternatif yang bisa dipakai adalah model Generalized Poisson Regression. Fungsi peluang Generalized Poisson ditunjukkan persamaan (6) yaitu [12]

$f(y \mid, \quad)=\left[\frac{}{1+}\right] \frac{(1+y)^{y}}{y !} \exp \left(\frac{(1+y)}{1+}\right)$

Karakteristik dari model ini yaitu

$$
\begin{aligned}
& E(y)= \\
& \operatorname{Var}(y)=(1+\quad)^{2}
\end{aligned}
$$

Distribusi Generalized Poisson memiliki dua parameter yaitu dan yang disebut parameter overdispersi. Persamaan (7) dan (8) merupakan model regresi yang bersesuaian dengan distribusi peluang ini adalah

$$
\begin{aligned}
& \boldsymbol{\mu}\left(\mathbf{x}_{i}, \boldsymbol{\beta}\right)=\exp \left(\mathbf{x}_{i} \boldsymbol{\beta}\right) \\
& \ln \left({ }_{i}\right)={ }_{0}+{ }_{1} x_{1 i}+{ }_{2} x_{2 i}+\ldots+{ }_{1} x_{k i}
\end{aligned}
$$

Sebagaimana model regresi Poisson, estimasi parameter model Generalized Poisson Regression juga dilakukan dengan bantuan metode MLE.

\section{Tahapan Analisis Data}

Tahap-tahap analisis data dalam penelitian ini adalah sebagai berikut

1. Input data kelimpahan fitoplankton dan konsentrasi nitrat dan fosfat

2. Menganalisis secara deskriptif komposisi dan kelimpahan fitoplankton

3. Membuat model regresi Poisson antara jumlah fitoplankton yang diamati menurut jenis divisi yang dibandingkan terhadap divisi Cholorophyta ( $\mathrm{D}_{1}$ : Chrysophyta ; $\mathrm{D}_{2}$ : Cyanophyta, $D_{3}$ : Euglenophyta), serta dengan konsentrasi nitrat $\left(\mathrm{X}_{1}\right.$ dan $\left.\mathrm{X}_{2}\right)$ dan fosfat

4. Menguji overdispersi dengan hipotesis $\mathrm{H}_{0}$ : equidispersi (rasio rata-rata terhadap ragam sama dengan 1)

$\mathrm{H}_{1}$ : overdispersi (rasio rata-rata terhadap ragam lebih dari 1)

5. Bila terjadi overdispersi maka dilanjutkan dengan pemodelan Generalized Poisson Regression

6. Menghitung prediksi kelimpahan fitoplankton berdasarkan ketersediaan nutrient

Proses analisis dibantu dengan software $\mathrm{R}$ for MacOS (Mojave) versi 3.6.1 dengan memanfaatkan beberapa packages yaitu VGAM, AER, ggplot2, msm, dan sandwich.

\section{HASIL DAN PEMBAHASAN}

\section{Komposisi dan Kelimpahan Fitoplankton di Ranu Grati}

Hasil identifikasi fitoplankton yang ada di perairan Ranu Grati menunjukkan bahwa struktur komunitas fitoplankton terdiri atas empat divisi yaitu Chlorophyta, Cyanophyta, Chrysophyta dan Euglenophyta sebagaimana ditunjukkan pada Gambar 2. 


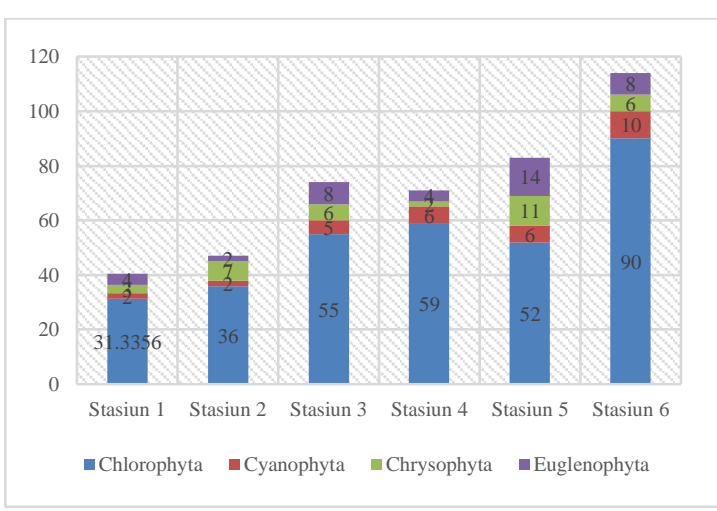

Gambar 2. Komposisi dan kelimpahan fitoplankton di Ranu Grati

Dari keempat divisi yang ada, divisi Chlorophyta paling mendominasi kelimpahan fitoplankton yang ada di Ranu Grati dengan persentase lebih dari 50\% pada masing-masing stasiun. Adapun total kelimpahan fitoplankton tertinggi ditemukan di stasiun 6 yang merupakan bagian tengah dari danau. Hal ini dikarenakan tengah danau merupakan lokasi berkumpulnya aliran air danau yang berasal dari berbagai sumber sehingga kaya akan bahan organic yang mendukung pertumbuhan fitoplankton.

\section{Hasil Pengujian Overdispersi}

Pengujian overdispersi dilakukan terhadap fitting model regresi Poisson. Hasil pengujian ditampilkan pada Tabel 1.

Tabel 1. Hasil Uji Overdispersi Model Regresi Poisson

\begin{tabular}{cc}
\hline Statistik & Nilai Estimasi \\
\hline Rasio rata-rata & \\
terhadap ragam & 1.992 \\
distribusi Poisson & \\
Wald $(\mathrm{z})$ & 2.715 \\
p-value & 0.003 \\
\hline
\end{tabular}

Berdasarkan Tabel 1 dapat diketahui bahwa nilai estimasi rasio rata-rata terhadap ragam sebesar $1.992>1$ yang menunjukkan terjadinya overdispersi. Hal ini diperkuat dengan pengujian hipotesis overdispersi yang menghasilkan $p$-value $=0.003$, di mana nilai tersebut lebih dari taraf signifikansi 5\% sehingga keputusan yang diambil adalah Tolak $\mathrm{H}_{0}$. Dengan demikian dapat diambil kesimpulan bahwa terjadi overdispersi pada data yang dianalisis dengan model regresi Poisson. Oleh karena itu, perlu dilakukan pemodelan dengan model Generalized Poisson Regression.

\section{Model Generalized Poisson Regression}

Hasil estimasi parameter model Generalized Poisson Regression disajikan pada Tabel 2 berikut ini.

Tabel 2. Hasil Estimasi Parameter Model Generalized Poisson Regression

\begin{tabular}{lcccc}
\hline Parameter & $\begin{array}{c}\text { Estimasi } \\
\text { Parameter }\end{array}$ & $\begin{array}{c}\text { Standar } \\
\text { Error }\end{array}$ & $\mathbf{Z}$ & $\begin{array}{c}\text { P- } \\
\text { value }\end{array}$ \\
\hline$\mu$ & 0.7313 & 0.1533 & 4.769 & 0.000 \\
$\alpha$ & 0.6267 & 0.4611 & 1.359 & 0.174 \\
Nitrat & 0.3356 & 0.1804 & 1.860 & 0.063 \\
Fosfat & 8.1859 & 3.1359 & 2.610 & 0.009 \\
Divisi & -2.0030 & 0.2357 & - & 0.000 \\
Chrysophyta & & & 8.499 & \\
Divisi & -2.1425 & 0.2492 & - & 0.000 \\
Cyanophyta & & & 8.596 & \\
Divisi & -2.0854 & 0.2436 & - & 0.000 \\
Euglenophyta & & & 8.561 & \\
\hline
\end{tabular}

Berdasarkan Tabel 2, maka dapat dibuat model Generalized Poisson Regression sebagai berikut

$$
\begin{aligned}
& f\left(y_{i}\right)=\left[\frac{i}{1+0.6267}\right] \frac{\left(1+0.6267 y_{i}\right)^{y_{i} 1}}{y_{i} !} \exp \left(\frac{\left.i^{(1+} y_{i}\right)}{1+}\right) \\
& \text { Dengan } \\
& i=\left(\mathbf{x}_{i}\right)=\exp \left(0.7313+0.3356 x_{1 i}+8.1859 x_{2 i}\right. \\
& \left.2.0030 d_{1 i} \quad 2.1425 d_{2 i} \quad 2.0854 d_{3 i}\right)
\end{aligned}
$$

Tabel 2 memperlihatkan bahwa baik fosfat maupun nitrat berpengaruh positif terhadap jumlah fitoplankton karena keduanya memiliki estimasi parameter yang bernilai positif. Estimasi parameter terhadap koefisien predictor Fosfat menunjukkan bahwa setiap kenaikan konsentrasi fosfat sebesar $1 \mathrm{mg} / \mathrm{L}$ akan mengakibatkan jumlah fitoplankton yang diamati (n) meningkat sekitar 8 sel, yang setara dengan kelimpahan fitoplankton sebesar 86204 sel/L. Di sisi lain, setiap peningkatan konsentrasi nitrat sebesar $1 \mathrm{mg} / \mathrm{L}$ hanya berdampak pada peningkatan jumlah amatan fitoplankton sekitar 0.33 atau setara dengan kelimpahan fitoplankton sebesar $3616 \mathrm{sel} / \mathrm{L}$. Dari hasil uji signifikansi juga bahwa fosfat berpengaruh signifikan terhadap hasil pengamatan kelimpahan fitoplankton (pvalue $=0.009)$. Di sisi lain, nitrat tidak berpengaruh signifikan $\quad(p$-value $=0.063)$. Pengaruh kedua variable tersebut diuji pada taraf signifikansi 5\%. 
Selain itu, dilihat dari jumlah amatan fitoplankton per divisi, maka fitoplankton dari divisi Chrysophyta, Cyanophyta dan Euglenophyta secara statistic memiliki jumlah amatan yang lebih kecil dibandingkan divisi Chlorophyta. Hal ini ditunjukkan oleh koefisien ketiga kategori tersebut pada Tabel 3 yang bernilai negatif. Ilustrasi grafik yang menunjukkan prediksi jumlah amatan fitoplankton per divisi terhadap fosfat (prediktor yang berpengaruh signifikan) ditampilkan pada Gambar 3.

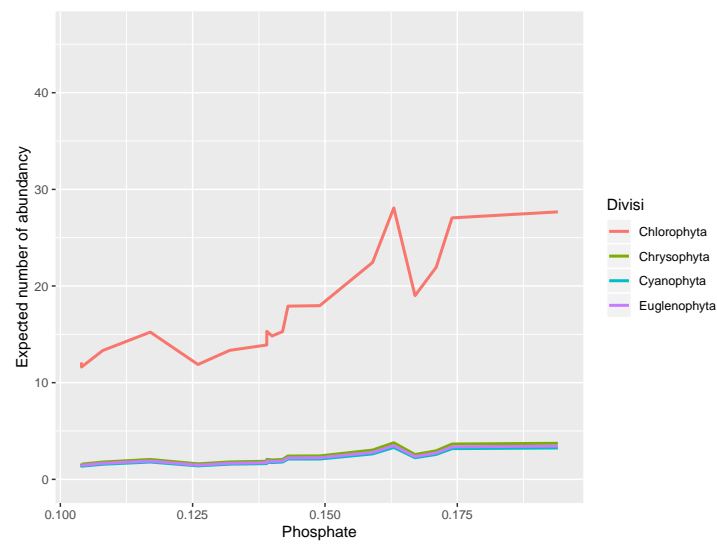

Gambar 3. Nilai Prediksi Jumlah Amatan Fitoplankton Per Divisi

Gambar 3 mengindikasikan bahwa jumlah amatan fitoplankton dari semua divisi fitoplankton mengalami peningkatan pada setiap perubahan konsentrasi fosfat. Peningkatan paling besar terjadi pada fitoplankton yang berasal dari divisi Chlorophyta. Hal ini menunjukkan bahwa peningkatan ketersediaan nutrien di Ranu Grati akan berdampak pada semakin dominannya fitoplankton dari divisi Chlorophyta. Kondisi ini disebabkan karena Chlorophyta memiliki kemampuan untuk bertumbuh lebih cepat dibandingkan fitoplankton dari divisi lainnya [17]. Namun, pertumbuhan Chlorophyta yang berlebihan akan berdampak buruk bagi perairan. Salah satunya adalah genus Ulva dari divisi Chlorophyta yang dapat menimbulkan racun atau toksin yang berbahaya bagi organisme akuatik lainnya speerti moluska [18].

\section{KESIMPULAN}

Berdasarkan hasil penelitian ini dapat disimpulkan bahwa terjadi overdispersi pada data hubungan ketersediaan nutrient dan jumlah amatan fitoplankton di Ranu Grati sehingga pemodelan dilakukan dengan Generalized Poisson Regression. Hasil analisis yang dilakukan menunjukkan nutrient yang berpengaruh signifikan terhadap jumlah amatan fitoplankton adalah fosfat. Adapun divisi fitoplankton yang diprediksi akan sangat terpengaruh oleh perubahan ketersediaan nutrient adalah yang berasal dari divisi Chlorophyta.

\section{UCAPAN TERIMA KASIH}

Penelitian ini terlaksana dengan sumber dana dari PNBP FPIK-UB. Penulis mengucapkan terima kasih kepada semua pihak yang telah membantu penelitian ini.

\section{DAFTAR PUSTAKA}

[1] A. Yulesti, H. Ekwarso, and T., "Analisis Kelayakan Danau Tajwid (Kajuid) sebagai Objek Wisata di Kecamatan Langgam Kabupaten Pelalawan," J. Online Mhs. Fak. Ekon. Univ. Riau, vol. 4, no. 1, pp. 12441254, 2017.

[2] Suchaina, "Pengaruh Kualitas Fasilitas Sarana dan Prasarana Terhadap Peningkatan Jumlah Pengunjung Danau Grati ," J. Psikol., vol. 2, no. 2, pp. 89-109, 2014.

[3] A. M. Suryanto, "Abundance and Phytoplankton Composition in Selorejo Reservoir, Ngantang District, Malang Regency," J. Kelaut., vol. 4, no. 2, pp. 34-39, 2011.

[4] D. B. Donald, M. Bogard, K. Finlay, L. Bunting, and P. Leavitt, "Phytoplankton-Specific Response to Enrichment of Phosphorus-Rich Surface Waters with Ammonium, Nitrate, and Urea," PLoS One, vol. 8, no. 1, pp. 1-14, 2013.

[5] B. Bhagowati and K. U. Ahamad, "A review on lake eutrophication dynamics and recent developments in lake modeling," Ecohydrol. \&Hydrobiology, vol. 19, no. 1, pp. 155166, 2019. 
[6] K. Paiki and J. D. Kalor, "Distribusi Nitrat dan Fosfat Terhadap Kelimpahan Fitoplankton di Perairan Pesisir Yapen Timur," J. Fish. Mar. Sci., vol. 1, pp. 65-71, 2017.

[7] Isnaini, H. Surbakti, and R. Aryawati, "Komposisi dan Kelimpahan Fitoplankton di Perairan Sekitar Pulau Maspari, Ogan Komering Ilir," Maspari J., vol. 6, no. 1, pp. 39-45, 2014.

[8] F. D. M. Putri, E. Widyastuti, and Christiani, "Hubungan Perbandingan Total Nitrogen dan Total Fosfor dengan Kelimpahan Fitoplankton di Perairan Waduk Panglima Besar Soedirman, Banjarnegara," Scr. Biol., vol. 1, pp. 96-101, 2014.

[9] A. Agresti, Categorical Data Analysis. New York: John Wiley \& Sons, 2002.

[10] E. L. Plan, "Modeling and Simulation of Count Data," CPT Pharmacometrics Syst Pharmacol, vol. 3, no. 8, 2014, [Online]. Available: https://www.ncbi.nlm.nih.gov/pmc/arti cles/PMC4150925/.

[11] A. C. Cameron and P. K. Trivedi, Regression Analysis for Count Data. Cambridge: Cambridge University Press, 1998.

[12] P. C. Consul and F. Famoye, Generalized Poisson Distribution: Properties and Applications. New York: USA: Marcel Dekker, 1989.

[13] E. H. Payne, M. Gebregziabher, J. W.
Hardin, V. Ramakrishnan, and L. E. Egede, "An empirical approach to determine a threshold for assessing overdispersion in Poisson and negative binomial models for count data," Commun. Stat. Simul. Comput., vol. 47, no. 6, pp. 1722-1738, Jul. 2018, doi: 10.1080/03610918.2017.1323223.

[14] H. Zamani and N. Ismail, "Score test for testing Poisson regression against generalized Poisson alternatives," AIP Conf. Proc., vol. 1522, pp. 1204-1212, 2013, doi: 10.1063/1.4801268.

[15] Z. Yang, J. W. Hardin, C. L. Addy, and Q. H. Vuong, "Testing approaches for overdispersion in poisson regression versus the generalized poisson model," Biometrical J., vol. 49, no. 4, pp. 565584, 2007, doi: 10.1002/bimj.200610340.

[16] A. C. Cameron and P. K. Trivedi, Microeconometrics, no. May 2005. London: Cambridge University Press, 2005.

[17] N. Manurung and T. R. Setyawati, "Produktivitas Primer Danau Lait Kecamatan Tayan Hilir Ditinjau dari Kelimpahan dan Kandungan Klorofil-a Fitoplankton," vol. 4, p. 10, 2015.

[18] P. Peckol and A. B. Putnam, "Differential toxic effects of Ulva lactuca (Chlorophyta) on the herbivorous gastropods, Littorina littorea and L. obtusata (Mollusca)," $J$. Phycol., vol. 53, no. 2, pp. 361-367, Apr. 2017, doi: https://doi.org/10.1111/jpy.12507. 